\title{
Influence of the Deposition Temperature on the Electrodeposition Mechanism of Zn-Co-Fe Alloy
}

\author{
O. K. Al-Duaij*, M. M. Abou-Krisha and M. I. Attia \\ College of Science, Chemistry Department, Al Imam Mohammad Ibn Saud Islamic University \\ (IMSIU), Riyadh 11623, KSA \\ *E-mail: okduaij@imamu.edu.sa
}

doi: $10.20964 / 2017.12 .62$

Received: 1 August 2017 / Accepted: 18 October 2017 / Published: 12 November 2017

\begin{abstract}
Steel was protected by coating its surface with a zinc-cobalt-iron alloy in a sulfate bath at different temperatures. Many techniques were used to analyse the composition, morphology and phase structure of the coating. A galvanostatic method was utilized to investigate the compositional and structural changes resulting from changes in the plating temperature. The results indicated that varying the deposition temperature led to anomalous and normal co-deposition of zinc, iron and cobalt. For temperatures higher than $50^{\circ} \mathrm{C}$, a sharp decrease in the current efficiency of the zinc-cobalt-iron codeposition was observed. The decrease in the current efficiency with the increase in the deposition temperature may be due to an increase in hydrogen evolution, which decreases the current efficiency of zinc. At $60^{\circ} \mathrm{C}$, sharp transformations in the compositions and phase structures of the zinc-cobaltiron alloy coatings were detected. The changes in the cathodic potential may have resulted in increased cobalt and iron contents in the zinc-cobalt-iron alloy coatings as the deposition temperature increased. The alloy showed a compact morphology and acceptable corrosion resistance when the temperature was in the $30-40^{\circ} \mathrm{C}$ range.
\end{abstract}

Keywords: Anomalous co-deposition, Zn-Co-Fe alloy, Electrochemical properties; Corrosion

\section{FULL TEXT}

(C) 2017 The Authors. Published by ESG (www.electrochemsci.org). This article is an open access article distributed under the terms and conditions of the Creative Commons Attribution license (http://creativecommons.org/licenses/by/4.0/). 